\title{
Research on countermeasures of self-driving tourism in Yunnan province
}

\author{
Wang Yuerong \\ Yunnan Open University
}

Keywords: yunnan province; Travel by car; countermeasures

\begin{abstract}
: this paper takes this region of yunnan province as an example, through analyzing the current situation of self-driving tourism in our province, discusses the advantages and disadvantages of developing self-driving tourism in our province, and then puts forward corresponding countermeasures, in the hope of providing theoretical guidance for self-driving tourism development in our province and providing certain ideas for promoting the development of self-driving tourism.
\end{abstract}

\section{Introduction}

Drive Travel refers to the market combination of products with great freedom and strong experience, which refers to that tourists make use of their spare time, organize themselves or be organized by self-driving operators, take private or rented cars as the main means of transportation, leave their permanent residence across a certain geographical space and leave home for at least one night. Self-driving tourism is characterized by autonomy, arbitrariness, openness, fashion, humanization and individualization. It also features strong stimulation, high consumption level and good experience. The term "self-driving travel" first appeared in the United States in the last century, which was popular in developed countries in the early years. In the beginning, people started to call their weekend drive (Sun day), which was later developed into drive travel. The Vehicle that real self-drivers use is/RV, which originated in the 1960s when americans called it Recreation Vehicle(RV). Self-driving tourism in our province only gradually rose in the 1990s. Limited by the economic development level in the province, the vehicles used by tourists are mainly household cars, multi-functional suvs and commercial vehicles (MPV). As the rise of self-driving tourism in our province is 30 years later than that in foreign countries, there is a large gap between our practice development and theoretical research level. However, in recent years, with the rapid development of the provincial economy, the increase of people's leisure time, the adjustment of national holiday system, the rapid development of self-driving tourism and gradually become an important form of mass tourism. The development time of self - driving tourism in our province is relatively short. In 2001, it began to appear spontaneously in the pearl river delta, Yangtze river delta and Beijing and tianjin, and in 2002, it was participated by car club and travel agency. Group driving Tours began to take shape. Since the golden week of National Day in 2003, driving Tours have become increasingly common in our province and become an important emerging market. In September 2004, the city of zhaoqing, guangdong province held BBS, the first Chinese self-driving tourism executive in the province, which attracted the attention of the tourism industry in the province. In recent years, yunnan province has been trying to build a famous tourist destination of self-drive in China and has made some achievements. Meanwhile, there are still some deep problems to be solved.

\section{Current situation and problems of self-driving tourism in yunnan province}

\subsection{Status quo of self-driving tourism in yunnan province}

The rapid development of highway traffic facilitates self-driving travel. In yunnan province, for example, it took eight or nine hours to get from the provincial capital of kunming to the city of Dali, which is just over 400 kilometers away, before the country's large-scale western development. Now the highway is ready, and it will be here in more than four hours. With the reform of oil roads in 
tongxian county and roads in tongxiang being carried out in a comprehensive way, it is more convenient and comfortable to travel through or to tourist areas, and it is no longer a dream for those who own private cars to travel by themselves in yunnan. Yunnan daily published an article on feb.3, 2006 on the 5 self-driving tourism craze yunling 6, which pointed out that, unlike the previous few golden weeks, this year's Spring Festival self-driving tour group has grown, not only including kunming tourists, but also many self-driving tourists from outside and within the province. Yunnan daily published an article on April 4, 2008 entitled "5 kunmun grand passage driving tourism along the route". It pointed out that self-driving outbound travel to Laos and Thailand will become a hot spot, which is believed to be popular with tourists. Soon, the China tourism daily reported on April 18,2008, and in March,2008, the yunnan provincial tourism industry held the 2008 China - yunnan four asean countries international business tourism self-driving inspection activities. This activity is a self-driving way, starting from kunming to the port of moten in yunnan province along the kunmun road that will soon open. It conducts the tourism business investigation and marketing for four countries, namely Laos, Thailand, Malaysia and Singapore. The event took 19 days and traveled over 9,000 kilometers, passing through more than 10 well-known states, governments or cities in the above four countries.

\subsection{Problems existing in self-driving tourism in yunnan province}

The current situation of self-driving tourism in our province indicates that this form of tourism will continue to develop and expand. However, due to the lack of standardization of self-driving tourism at present, regional governments and tourism departments pay different attention to the management of self-driving tourism, with poor linkage capacity of the departments. As a result, traffic safety, environmental damage, market standardization, reception services and other problems are also increasingly prominent.

\subsubsection{Administrative regulations lag behind and the whole market is in legal blind area.}

At present, self-driving travel is very popular with a large number of participants. However, at present, there is no specific laws and regulations for self-driving tourism, leaving the entire market in a legal blind area. First, at present, the overall scale of self-driving enterprises is relatively small, and tourists cannot distinguish the strength of self-driving enterprises. A lot of car dealers, car rental companies, car club, etc. who do not have tourism qualifications are engaged in self-driving Tours. The root cause of this disorderly competition situation is the lack of market access system in the auto industry. This makes the safety of the life and property of the tourists unimpeded. As the subject of administrative regulation, the national tourism administration has not formulated specific standards and norms for the qualification certification of self-driving operators, nor made clear provisions on the rights and obligations of self-driving operators. And there is no department to review operators' qualifications. Second, there are no clear regulations on self-driving vehicles and drivers. The self-driving vehicle is the main traffic load for self-driving tourism. There are no clear regulations on the standards that should be met by vehicles entering different routes, the status of vehicles and the charging standards of vehicles. The relevant qualifications and obligations of self-driving-drivers have not been determined. The relevant standards for different types of self-driving-drivers have been stipulated in the laws and regulations of the ministry.

\subsubsection{Market operation is not sound, supporting service system lags behind.}

Due to the lack of special laws and regulations and industrial norms, the self-driving operation subject is in chaos, resulting in the entire market in a chaotic state, which cannot form scale effect and cannot support various supporting facilities and service systems. This is reflected in :(1) the public transport marking system is not perfect. In particular, the traffic signs, warning signs and other indicators are short or unclear, there is a lack of travel advisory services on the road. (2) the construction of parking places and gas stations is becoming increasingly prominent. No matter the scenic spot or the shopping mall hotel in our province, there is a shortage of parking space. Gas station is the lifeline of self-driving tourism. Many self-driving tourists in the province are faced with the problem of lack of information channel of the gas station, and the service of gas station 
cannot meet the diversified demands.

\subsubsection{Security concerns are growing.}

From the Spring Festival and October 10 holiday in recent years, the personal and property safety of self-driving tourists is not optimistic. This has several reasons, one is the driver level is uneven, traffic safety accidents occur from time to time; Second, self-driving tourists lack a certain sense of safety. Many self-driving tourists often encounter the accident of robbery on the road and the theft of camping. Third, the industry service and management in the safety rescue organization capacity and construction are very weak, can not adapt to the current rapid development of self-driving tourism needs.

\subsubsection{The cost of self-driving travel is too high.}

Besides the original tourism consumption, there are many additional expenses such as tolls, gas, parking and washing. And I save the road charge is on the high side, increased the tourist's economic and psychological burden. Take kunming to tengchong for example, the toll is more than 200 yuan, and there are many places to charge parking fees. Although the amount is small, the frequency is high, which not only brings the economic burden to the tourists, but also often affects the emotions of the tourists and reduces the quality of tourism.

\section{Development countermeasures of self-driving tourism in yunnan province}

Although self-driving tourism in yunnan province has shown great realistic demand and broad development prospects, it is still in the initial stage overall, and there are still quite a few problems at all levels, which greatly restricts the development of self-driving tourism. Therefore, it is necessary to put forward countermeasures from various aspects that restrict the development of self-driving tourism and promote the rapid and healthy development of self-driving tourism.

\subsection{To introduce relevant administrative regulations and regulate industrial management}

At present, self-driving tourism in the province mainly includes three forms, including self-driving, self-driving group and self-driving tour operator planning, with many participants. For each subject, the relation of authority and responsibility must be clear. But there are no specific regulations to support law enforcement agencies. After relevant problems occur, tourism law enforcement agencies lack relevant regulations for reference and handling, which is a serious problem for tourists, operators, law enforcement agencies and industry management departments. Therefore, laws and regulations on self-driving tourism in the province should be issued and improved as soon as possible to protect the rights and interests of drivers and the tourism environment, and regulate the industry management with regulations and regulations.

\subsection{Strengthen contact with relevant government departments to obtain more support and cooperation}

In order to explore tourism resources, develop tourism products with local and ethnic characteristics, and hold activities such as special food, folk culture and festivals, all of these activities must be coordinated by relevant government departments. Because self-driving tourists are afraid of chaos; Fear of traffic jams; Third, fear of penalty. Without the help of government departments, they would regard the beautiful scenery and the urban landscape as dangerous. Therefore, how to strengthen the management of the city at the same time, convenient for self-driving owners to travel safely, is the problem that cannot be avoided everywhere.

\subsection{Improve the self-driving tourism service system}

Because of self-drive tourism in our province is still in its infancy, the whole service system is not fully established, at the same time the driving enthusiasts there are driving technique, psychological preparation, vehicles and other issues, which requires the related department to provide more detailed and thoughtful service, in line, gas stations, room and board, emergency 
rescue, maintenance and other aspects to ensure the driving safety. The security and service facilities of self-driving tourism mainly include four parts: first is the car camp, second is the motel, third is the fixed or flow support, supply and service facilities, fourth is the first aid and rescue facilities, including rescue and fire protection facilities. A temporary or permanent visitor service center, such as a highway service station, urban population or a busy area.

\subsection{Improve the safety system of self-driving}

At present, the provincial safety rescue organization and ability are not enough to adapt to the needs of self-driving travel. Conditions should be created to provide reliable protection for self-driving travel. Families, colleagues, or friends who travel by car often travel in groups of several vehicles. Because of the complexity of the vehicle and the technical differences of the driver, most organizers choose the route first to consider the traffic situation. To better attract self-driving tourists, the first step is to ensure the safety and smoothness of the route, but the high-level road is more important than the road condition. For example, the establishment of the vehicle rescue system, small to the traffic signs along the road, the suspension of the scenic spot guidance system, the prepositioning of the scenic spot, and so on are of great importance. Self-driving tourism needs safety, convenience, economy and fun. With these conditions, self-driving tourism can achieve substantial development.

\subsection{Our provincial campsite is in line with international standards}

Now there are specialized international camping organizations in the world, among which the influential one is the international camping association. Its headquarters is in Brussels, Belgium, and it is a non-governmental organization affiliated with the United Nations. It has 58 member states, whose aim is to promote friendly camping enthusiasts of all countries, advocate environmental tourism and protect the ecological environment. However, the construction of our provincial campsite is still a virgin land, which does not have a truly international standard campsite. As a result, many foreign tourists driving their own camping cars into yunnan encounter the awkward situation of no standard campsite. The car can only stay in the hotel and the staff can live in the hotel. Therefore, the construction of the campsite is the bottleneck that restricts the automobile camping movement in our province, and it is also the top priority of the automobile camping work in our province.

\subsection{Vigorously develop self-driving tourism-oriented scenic spots}

Self-driving tourism will become a new growth point of our province. Establish effective channels to guide the drive tourists choose target-oriented suits drive scenic areas, attractions, promote scenic areas, attractions on the infrastructure and service facilities can be more suitable for driving the special needs of tourists, can promote self-drive travel to this new way of tourism healthy and orderly development, it also requires developing road guide tourism scenic spots.

\section{References}

[1] Zhang Bo. Analysis of development status and problems of domestic/self-driving tourism 0. Journal of western chongqing university, 2004, (6).

[2] Lu Yao. Status quo and development countermeasures of self-driving tourism in China. Journal of new liao industrial and technical college, 2007, (6)3.

[3] Chen Gankang. Research on self-driving tourism market development [J]. Journal of tourism studies, 2004.

[4] Zhang Zhiyun, Yang qizhong. Overview of self-driving travel research. Tourism market research, 2009, 2(1).

[5] Zhou Wuzhong, zhu jianfeng. Study on planning of self-driven tourist attractions. Journal of southeast university (philosophy and social science edition), 2007, 9(5). 